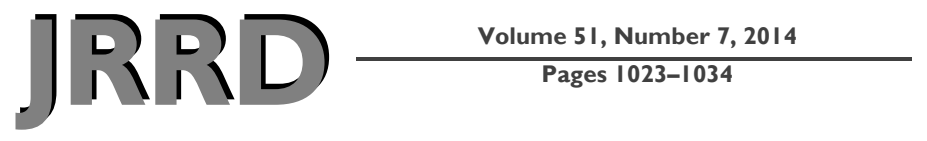

\title{
Factors associated with neurocognitive performance in OIF/OEF servicemembers with postconcussive complaints in postdeployment clinical settings
}

\author{
Douglas B. Cooper, PhD; ${ }^{1-2 *}$ Rodney D. Vanderploeg, PhD; ${ }^{1,3}$ Patrick Armistead-Jehle, PhD; ${ }^{4}$ Jeffrey D. Lewis, \\ MD, PhD; ${ }^{5}$ Amy O. Bowles, MD ${ }^{6}$ \\ ${ }^{1}$ Defense and Veterans Brain Injury Center, Silver Spring, MD; ${ }^{2}$ Department of Neurology, San Antonio Military Med- \\ ical Center, Fort Sam Houston, TX; ${ }^{3}$ James A. Haley Veterans' Hospital, Tampa, FL; and Departments of Psychiatry \\ and Neurosciences, and Psychology, University of South Florida, Tampa, FL; ${ }^{4}$ Concussion Clinic, Munson Army \\ Health Center, Fort Leavenworth, KS; ${ }^{5}$ Behavioral Neurology Unit, National Institute of Neurological Disorders and \\ Stroke, Bethesda, MD; ${ }^{6}$ Department of Orthopedics \& Rehabilitation, Traumatic Brain Injury Service, San Antonio \\ Military Medical Center, Fort Sam Houston, TX
}

\begin{abstract}
Cognitive difficulties are frequently reported by Operation Iraqi Freedom/Operation Enduring Freedom military personnel who sustained mild traumatic brain injuries (TBIs). The current study examined several potential factors that may contribute to self-reported cognitive difficulties in postdeployment clinical settings. Eighty-four subjects who sustained a mild or moderate TBI and reported cognitive difficulties underwent neurocognitive testing. Multiple regression analyses were used to determine the amount of variance in neurocognitive performance accounted for by the predictor variables (demographic, mechanism of injury, time since injury, headache severity, combat stress, postconcussive complaints, and effort/performance validity). The predictor variables collectively accounted for $51.7 \%$ of the variance in cognitive performance $(F(8,72)=11 / 99, p<0.001)$. The most potent predictor of cognitive functioning was performance validity/ effort, which uniquely accounted for $16.3 \%$ of the variance $(p<0.01)$. Self-reported symptom severity, including postconcussive complaints, combat stress, and headache intensity, accounted for $7.2 \%$ of the variance $(p<0.05)$. Demographic factors and injury characteristics, such as time since injury and mechanism of injury, were not significant predictive factors of cognitive performance. The findings of the current study underscore the need to include measurement of effort as part of neurocognitive evaluation in postdeployment settings when evaluating cognitive complaints associated with mild TBI.
\end{abstract}

Key words: blast injuries, cognitive complaints, combat veterans, mild traumatic brain injury, neuropsychological assessment, OIF/OEF, performance validity, postconcussive symptoms, postdeployment, posttraumatic stress disorder.

Abbreviations: ACRM = American Congress of Rehabilitation Medicine; AHLTA = Armed Forces Health Longitudinal Technology Application; BAMC = Brooke Army Medical Center; DOD = Department of Defense; DSM-IV-TR = Diagnostic and Statistical Manual of Mental Disorders, 4th Edition, Text Revision; DVBIC = Defense and Veterans Brain Injury Center; GCS = Glasgow Coma Scale; HIT-6 = Headache Impact Test; LOC = loss of consciousness; $\mathrm{mTBI}=$ mild traumatic brain injury; NSI = Neurobehavioral Symptom Inventory; OEF = Operation Enduring Freedom; OIF = Operation Iraqi Freedom; PCL-M = Posttraumatic Stress Disorder Checklist-Military Version; PTA = posttraumatic amnesia; PTSD = posttraumatic stress disorder; PVT = performance validity test; RBANS = Repeatable Battery for the Assessment of Neuropsychological Status; RBANS EI = RBANS Effort Index; TBI = traumatic brain injury; VA = Department of Veterans Affairs.

*Address all correspondence to Douglas B. Cooper, PhD; Defense and Veterans Brain Injury Center, San Antonio Military Medical Center, MCHE MDU (DVBIC), 3551 Roger Brooke Dr, JBSA Fort Sam Houston, TX 782344504. Email: douglas.b.cooper.ctr@mail.mil http://dx.doi.org/10.1682/JRRD.2013.05.0104 


\section{INTRODUCTION}

Traumatic brain injury (TBI) and the subsequent experience of postconcussive syndrome have been referred to as signature injuries among combat veterans involved in Operation Enduring Freedom (OEF) and Operation Iraqi Freedom (OIF). The Defense and Veterans Brain Injury Center (DVBIC) estimates that from 2001 through June 2011, approximately 267,000 individuals experienced a TBI during OIF/OEF operations [1]. The vast majority of these TBIs (i.e., approximately $80 \%$ ) meet criteria for the mild variant of this condition [1]. While servicemembers who experience mild TBI (mTBI) frequently report residual cognitive complaints postdeployment [2-3], objective performances on neurocognitive measures have been shown to correlate poorly with subjective reports of cognitive symptoms in this patient population [2,4-5].

A range of factors could result in the cognitive complaints reported by these servicemembers in postdeployment settings. A number of studies have found increases in subjective reports of cognitive difficulties in those with chronic pain [6-7]. Additionally, objective deficits have been demonstrated in both acute and chronic pain samples in a number of cognitive domains, including memory, attention, verbal fluency, and processing speed [8-9]. Sleep difficulties can also potentially affect neurocognitive functioning and/or perception of cognitive functioning. The literature generally suggests that while adults with insomnia report cognitive deficits, differences on objective neurocognitive measures between patients diagnosed with insomnia and controls are at best inconsistently found. For instance, a study by Orff et al. demonstrated that while their sample diagnosed with primary insomnia reported greater subjective cognitive deficits than a nondisabled control group, there were no differences in objective performances across measures of attention, motor speed, verbal fluency, or verbal learning and memory [10]. This conclusion has been replicated in other samples [11-13]. As such, while the current literature fails to consistently demonstrate an association between insomnia and objective cognitive deficits, it does suggest that sleep disturbance contributes to selfreported cognitive difficulties.

Given that an estimated 19 to 44 percent of combat veterans return from OIF/OEF deployments with mental health symptoms or diagnoses [14-15], such factors are of importance when considering the source of self- reported or objective cognitive deficits in postdeployment servicemembers. For instance, clinical depression (or associated symptoms such as fatigue or limited motivation) have also been shown to variably affect neurocognitive test performances across a range of domains [5,16-17]. However, as with insomnia, other studies have demonstrated that depression is not necessarily associated with objective neurocognitive decline [18-19] and may, then, relate only to self-reported cognitive abilities. A diagnosis of posttraumatic stress disorder (PTSD) has been associated with diminished neuropsychological testing across a number of domains, including processing speed $[5,20]$, attention and executive functioning [5,2124], and memory [5,24-26]. (For a review of neuropsychological findings in PTSD, see Vasterling and Brailey [16]). Of note, few of these studies have considered the potential effect of performance validity on cognitive test performances. Consequently (and similar to clinical depression), the effect of PTSD on cognitive functioning could be circumscribed to subjective report rather than objective deficits.

A potentially obvious source of variance when attempting to account for the cognitive deficits reported by postdeployment servicemembers is their history of brain injury. A large body of research has found that moderate and severe TBI can have long-term influences on cognitive functioning (for a review, see Dikmen et al. [27]). However, the extant literature largely suggests that a history of mTBI has few (if any) lasting symptoms and that any degree of postconcussive symptoms experienced after such an injury is likely a result of multiple factors, including nonneurological causes [27-31].

In the recent past, an accumulating number of studies [32-34] have demonstrated that effort has a more pervasive influence on neurocognitive test performance than do clinical or demographic factors. For instance, Meyers et al. demonstrated that 50 percent of the variance in a full neuropsychological test battery was accounted for by failure on a comprehensive system of internal performance validity tests (PVTs) [35]. These findings are of particular importance in postdeployment settings, in which a notable number of patients have been shown to evidence suboptimal effort on various PVTs [36-38], especially when examined in the context of Department of Veterans Affairs (VA) disability determination [3940]. Note that these studies may not be representative of the entire military and VA population, because they primarily examined individuals seeking care and/or service 
connection in the VA system and only a small percentage of individuals who sustain injuries during deployment are represented in these samples. However, an empirical examination of effort in postdeployment clinical settings appears warranted.

The primary aim of the current study was to investigate the effect of various factors, including effort, demographics, symptom complaints, and potential comorbidities, on neurocognitive functioning in servicemembers who sustained a concussion and reported cognitive difficulties following combat deployments to Iraq or Afghanistan. We hypothesized that effort, psychiatric comorbidity, and chronic pain would have the greatest effects on neurocognitive performance in this sample. Our secondary aim was to examine whether other factors, such as demographics, injury characteristics, combat stress, and/or symptom complaints, were contributing to lower performance on cognitive testing in those individuals determined to have been putting forth adequate effort. Although similar studies have been conducted in specialty samples [41], this study is one of the first to examine these factors in a postdeployment general clinical sample.

\section{METHODS}

\section{Participants and Procedures}

This archival study was approved by the institutional review board at Brooke Army Medical Center (BAMC). Participants were identified from OIF/OEF military servicemembers presenting to the TBI Clinic at BAMC for treatment of suspected/known mTBI between January 2008 and January 2010. Initial screening of the sample and diagnosis of TBI were made through record review (see next paragraph for further details) and a semistructured clinical interview conducted by either a physician, physician assistant, or advanced nurse practitioner. Individuals with cognitive complaints were subsequently referred for neurocognitive screening as part of comprehensive work-up and treatment recommendations. A total of 120 servicemembers completed neurocognitive screening and served as the sample pool for the current investigation. None of the neurocognitive evaluations were completed as part of a medical evaluation board (military disability) proceeding. Twenty-six subjects were excluded because of missing data on one or more variables of interest (i.e., demographic, injury characteristics, symptom self-report). Six subjects were excluded because they were determined not to have sustained a TBI and four because they sustained a severe or penetrating TBI. A majority were male (89.3 percent) with a history of having mTBI (96.4\% mTBI, 3.6\% moderate TBI). Other injuries included burns (3.6\%) and amputations (9.5\%), although all could complete neurocognitive testing without modification. These are overlapping categories in that several individuals had more than one type of injury.

The Department of Defense (DOD) utilizes an electronic medical record system, the Armed Forces Health Longitudinal Technology Application (AHLTA), that contains built-in templates that guide the provider with specific questions and prompts that the clinician can use to elaborate if necessary. The specific AHLTA template developed for mTBI was used to structure these interviews. Diagnosis of mTBI (concussion) was operationally defined as one or more of the following: loss of consciousness (LOC) of approximately 30 min or less; loss of memory for events immediately before (retrograde amnesia) or after the injury event (posttraumatic amnesia [PTA] <24 h); self-report of feeling dazed, disoriented, or confused (alteration in mental state) at the time of the injury; or Glasgow Coma Scale (GCS) score $\geq 13$ or the presence of focal neurological deficits immediately following the event. This diagnosis of mTBI is consistent with the American Congress of Rehabilitation Medicine (ACRM) criteria [42]. Moderate TBI was defined as duration of PTA $>24 \mathrm{~h}$ but $<7 \mathrm{~d}$, GCS score of $9-12$, and/or LOC $>30$ min but $<24$ h. Individuals who met ACRM criteria for mTBI but whose records documented positive neuroimaging findings were classified as having a moderate TBI, consistent with current DOD guidance [43]. GCS scores were not always available in medical records. When GCS scores were available, the lowest postresuscitation GCS score was used to operationalize TBI severity. LOC and alteration of consciousness were based on retrospective self-report.

Time since injury to evaluation was calculated and ranged from 5-2,049 d. Fifty percent of the sample had their injury within the last $4.5 \mathrm{mo}$ and eighty percent within the last $1.5 \mathrm{yr}$. In order to use this variable in prediction analyses and not have it be adversely affected by outliers, we recorded individuals with a time since injury $>1.5 \mathrm{yr}$ as $550 \mathrm{~d}$ postinjury. The study population was divided into two subgroups on the basis of etiology of the interview-confirmed mTBI diagnosis: blast $(n=51)$ and nonblast $(n=33)$. If blast was one of multiple mechanisms of injury, the participant was assigned to the blast group. In 
those individuals who reported more than one concussion, the most recent concussive event was used to calculate time since injury.

The final sample consisted of 84 individuals, all of whom were at least $18 \mathrm{yr}$ of age, spoke English, and had sustained an injury while on Active Duty military service. Demographic, injury characteristics, and symptom complaint data are presented in Table 1.

\section{Measures}

\section{Cognitive Functioning}

The Repeatable Battery for the Assessment of Neuropsychological Status (RBANS) [42,44] was administered as a neurocognitive screening instrument as part of the initial work-up in the TBI Clinic. The RBANS was administered as a stand-alone instrument and was not used in combination with a larger battery of neuropsychological tests. The RBANS is a widely used measure of cognitive functioning and provides five domain index scores (i.e., immediate memory, visuospatial/constructional, language, attention, and delayed memory) and a combined total index score. The RBANS has been validated to assess cognitive functioning among a variety of populations, including TBI [45]. An Effort Index (RBANS EI) was calculated for the RBANS based on the work of Silverberg et al. [46] using digit span and memory recognition raw scores. Individuals with an RBANS EI greater than zero (i.e., list recognition $<18$ or digit span $<8$ ) were classified as invalid. Individuals with an

Table 1.

Demographic, injury, and symptom characteristics $(n=84)$. Data presented as mean \pm standard deviation unless otherwise indicated.

\begin{tabular}{lc}
\hline \multicolumn{1}{c}{ Characteristic } & Value \\
\hline Age (yr) & $30.93 \pm 7.53$ \\
Sex (Male), $n(\%)$ & $75(89.3)$ \\
Blast Mechanism (Yes), $n(\%)$ & $354.43 \pm 457.02$ \\
Days Postinjury & $244.49 \pm 210.85$ \\
Days Postinjury Recoded ${ }^{*}$ & $56.56 \pm 10.11$ \\
HIT-6 Total Score & $34.52 \pm 17.67$ \\
NSI Total Score & $42.55 \pm 17.78$ \\
PCL-M Total Score & $91.31 \pm 16.22$ \\
RBANS Total Score & \\
"Subjects >1.5 yr postinjury were recoded to 550 d. \\
HIT-6 = Headache Impact Test, NSI = Neurobehavioral Symptom Inventory, \\
PCL-M = Posttraumatic Stress Disorder Checklist-Military Version, RBANS = \\
Repeatable Battery for the Assessment of Neuropsychological Status. \\
\hline \hline
\end{tabular}

RBANS EI of zero were classified as valid for the purposes of analysis.

\section{Posttraumatic Stress}

The Posttraumatic Stress Disorder Checklist-Military Version (PCL-M) is a 17-item survey used to screen for PTSD [47]. Items in this self-report questionnaire parallel the Diagnostic and Statistical Manual of Mental Disorders, 4th Edition, Text Revision (DSM-IV-TR) symptoms for PTSD diagnosis, and can be separated into the DSMIV-TR's B, C, and D diagnostic criteria (re-experiencing, avoidance, and hyperarousal) for provisional PTSD diagnosis. Respondents are instructed to indicate the level to which each symptom bothered them in the last month, and each item response ranges from 1 (not at all) to 5 (extremely); total scores range from 17-85. A 5-10 point change is considered reliable, and a 10-20 point change is considered significant. The military version (PCL-M) asks questions specifically about symptoms related to military experiences and has been validated in veteran and military samples [48]. For the current study, PCL-M raw scores were used to capture the degree of PTSD symptom severity.

\section{Postconcussive Symptoms}

The Neurobehavioral Symptom Inventory (NSI) is a 22-item survey addressing symptoms that may be present following a concussion [49]. This self-report survey includes questions covering four basic domains: somatic, cognitive, sensory, and affective. Respondents are instructed to rate the severity of each item based on the degree to which the symptom has disturbed them in the last $2 \mathrm{wk}$, using a scale from 0 (none) to 4 (very severe); total scores range from 0-44. Several factor analyses of the NSI have been completed in samples of OIF/OEF veterans and military personnel. When controlling for PTSD symptoms, one recent factor analysis found a fourfactor solution including cognitive, affective, physical, and somatic symptoms [50]. A three-factor solution (affective, cognitive, and sensory/somatic clusters) was reported through factor analysis of three military OIF/ OEF samples [51].

\section{Headache Intensity}

The Headache Impact Test (HIT-6) is a brief, six-item questionnaire measuring headache severity and its effect on daily functioning. It was developed using item response theory to provide a brief measure of headache-related 
disability [52]. Given the finding of increased headache in blast-injured individuals in a prior investigation [53], a specific measure of headache intensity was included in the study.

\section{Statistical Analysis}

First, analyses of variance were used to compare the valid RBANS group with the invalid RBANS group on RBANS performance. Then, hierarchical logistic regression analyses were used to examine the relationship between cognitive functioning and the following possible predictor variables: demographic characteristics (age and sex), injury characteristics (blast vs nonblast mechanism of injury, time since injury), symptom complaints (HIT-6, NSI, and PCL-M), and effort (RBANS EI). Sex, mechanism of injury, and RBANS EI were examined as dichotomous variables. Variables were entered in blocks. To determine the unique contribution of each set of predictor variables, we entered each block last relative to all other blocks of predictors. The change in variance associated with the last step represents the unique contribution of that set of predictors. These analyses were first completed for the entire sample $(n=84)$ and then re-run on the smaller sample with an RBANS EI of zero (valid RBANS EI subsample, $n=60$ ).

These analyses were run twice, first using the RBANS Total Score and then using a computed score eliminating the RBANS indices that included scores used to calculate the RBANS EI. This was accomplished by using principal components factor analysis to extract and save the factor scores for the unrotated one-factor solution using the following RBANS raw scores as independent variables: list learning, story memory, figure copy, line orientation, picture naming, semantic fluency, coding, list recall, story recall, and figure recall. Digit span and list recognition were not included in these analyses, and they are used to compute the RBANS EI. Factor scores were significantly correlated with the RBANS Total Score $(r=0.91, p<0.001)$.

\section{RESULTS}

Demographics, injury variables, symptom complaint, and overall RBANS performance data are presented in Table 1. The RBANS scores are interval data with a normative mean of 100 and a standard deviation of 15. Collectively, participants performed in the lower end of the average range on the RBANS. Table 2 shows the difference in RBANS performance between those classified as valid versus invalid by the RBANS EI. The effect size for validity is large in all cases. Using the entire sample, hierarchical logistic regression analyses were used to examine the predictors of overall RBANS performance.

Table 3 shows that, collectively, predictor variables accounted for 57.1 percent of the variance in RBANS performance $(F(8,72)=11.99, p<0.001)$. The most potent predictor was the RBANS EI, uniquely accounting for 16.3 percent of the variance $(p<0.01)$. Symptom severity measures (HIT-6, PCL-M, NSI) were also statistically significant, accounting for 7.2 percent of the variance in RBANS performance $(p<0.05)$. Injury characteristics uniquely accounted for only 1.4 percent (nonsignificant), and demographic factors uniquely accounted for 1.3 percent (nonsignificant) in RBANS Total Score. However, note that most of the predictive variance was shared among the predictor variables (30.9\%).

Table 3 also shows the variables accounting for variance in the RBANS Factor Score (eliminating digit span and list recognition, variables used to calculate the RBANS EI). The RBANS EI was the only variable significantly predictive of the overall RBANS performance $(18.7 \%$

Table 2.

Cognitive performance by domains as well as by valid versus invalid Repeatable Battery for the Assessment of Neuropsychological Status performance. Data presented as mean \pm standard deviation.

\begin{tabular}{lccccc}
\hline \multicolumn{1}{c}{ Domain } & All Participants $(\boldsymbol{n}=\mathbf{8 4})$ & Valid $(\boldsymbol{n}=\mathbf{6 0})$ & Invalid $(\boldsymbol{n}=\mathbf{2 4})$ & $\boldsymbol{d}$ & $\boldsymbol{p}$-Value \\
\hline Immediate Memory & $88.76 \pm 15.17$ & $92.63 \pm 12.73$ & $79.08 \pm 16.65$ & 0.89 & 0.001 \\
Delayed Memory & $87.64 \pm 21.40$ & $97.18 \pm 15.25$ & $63.79 \pm 15.00$ & 1.56 & 0.001 \\
Language & $91.83 \pm 15.55$ & $96.42 \pm 13.45$ & $80.38 \pm 14.70$ & 1.03 & 0.001 \\
Visuospatial & $108.14 \pm 12.62$ & $111.62 \pm 10.70$ & $99.46 \pm 13.08$ & 0.96 & 0.001 \\
Attention & $91.13 \pm 18.26$ & $96.82 \pm 15.64$ & $76.92 \pm 16.74$ & 1.09 & 0.001 \\
Total & $91.31 \pm 16.22$ & $98.12 \pm 11.59$ & $74.29 \pm 13.51$ & 1.47 \\
Note: Effect size $(d)$ represents differences between valid and invalid cases. & & & & & \\
\hline \hline
\end{tabular}


JRRD, Volume 51, Number 7, 2014

Table 3.

Variance in Repeatable Battery for the Assessment of Neuropsychological Status (RBANS) Total Score Index explained by independent variables for all participants $(n=84)$.

\begin{tabular}{|c|c|c|c|c|}
\hline \multirow[b]{2}{*}{ Variable (\%) } & \multicolumn{2}{|c|}{ RBANS Total Score } & \multicolumn{2}{|c|}{ RBANS Factor Score } \\
\hline & $\begin{array}{l}\text { Block Unique } \\
\text { Variance }\end{array}$ & $\begin{array}{c}\text { Variable Unique } \\
\text { Variance }\end{array}$ & $\begin{array}{c}\text { Block Unique } \\
\text { Variance }\end{array}$ & $\begin{array}{c}\text { Variable Unique } \\
\text { Variance }\end{array}$ \\
\hline Demographic & 1.3 & - & 3.1 & - \\
\hline Injury Characteristics & 1.4 & - & 1.3 & - \\
\hline Symptom Measures & $7.2^{*}$ & - & 3.8 & - \\
\hline HIT-6 & - & 0.1 & - & 0.6 \\
\hline PCL-M & - & 0.1 & - & 0.0 \\
\hline Validity (RBANS EI) & $16.3^{\dagger}$ & - & $18.7^{\dagger}$ & - \\
\hline Total Variance & $57.1^{\dagger}$ & - & $57.1^{\dagger}$ & - \\
\hline Shared Variance & $30.9^{\dagger}$ & - & $30.2^{\dagger}$ & - \\
\hline \multicolumn{5}{|c|}{$\begin{array}{l}\text { Note: Demographic variables = age and sex. Injury characteristics = blast-mechanism of injury and time since injury. RBANS Factor Score = unrotated factor score } \\
\text { for one-factor solution of all RBANS subtest raw scores except digit span and list recognition (subtests used to calculate RBANS EI). } \\
{ }^{*} p<0.05 . \\
{ }^{\dagger} p<0.01 . \\
\text { EI = Effort Index, HIT-6 = Headache Impact Test, NSI = Neurobehavioral Symptom Inventory, PCL-M = Posttraumatic Stress Disorder Checklist-Military Version. }\end{array}$} \\
\hline
\end{tabular}

unique variance). Injury characteristics uniquely accounted for 1.3 percent (nonsignificant), and demographic factors uniquely accounted for only 3.1 percent (nonsignificant) in RBANS Factor Score. Again, most of the predictive variance was shared among the predictor variables (30.2\%).

Within those participants classified as passing the RBANS EI $(n=60)$, analyses were conducted to examine whether demographic, injury, or symptom self-report measures would be predictive of neurocognitive performance. Table 4 shows that, collectively, predictor variables accounted for 16.7 percent of the variance in RBANS performance $(F(7,49)=1.40, p=0.23)$. No block of variables or any individual variable was a statistically significant predictor, although the symptom measures collectively accounted for 11.3 percent of the unique variance in RBANS performance $(p=0.10)$. Similarly, no block of variables or any individual variable was a statistically significant predictor of the RBANS Factor Score (i.e., eliminating digit span and list recognition scores).

\section{DISCUSSION}

The current study sought to examine the potential influence of various demographic, injury characteristics, symptom complaint, and effort variables on the neuropsychological functioning of postdeployment Active Duty servicemembers with cognitive complaints. Predictor variables in regression analysis accounted for roughly 57 percent of the variance in the neurocognitive screening measure employed. Injury characteristics (e.g., time since injury and blast mechanism of injury status) and demographic variables (e.g., age and sex) were not significant in the current model. Measures examining the severity of reported headache, neurologic, and PTSD symptoms were statistically significant, but together uniquely accounted for only 7 percent of the variance in neurocognitive performance. By far the most potent unique predictor of neurocognitive performance in the current study was test taker effort as measured by the RBANS EI, which accounted for $>16$ percent of the variance.

In the current study, 29 percent of the sample failed the RBANS EI. A study by Armistead-Jehle and Hansen found only a 14 percent failure rate on the RBANS EI (cut score of $\geq 1$ ) in their military sample [37]. However, Armistead-Jehle and Hansen asserted that patient cohort appeared to have an effect on PVT performance and that the RBANS EI failure rate reported in this study collapsed two groups with different base rates of stand-alone PVT failure. More specifically, the study reported select PVT data on midlevel officers currently enrolled in a nearly yearlong Command and General Staff College training course and others not enrolled in this course. It was asserted that the latter group was more representative of the Active Duty population in terms of age, rank, and 
Table 4.

Variance in Repeatable Battery for the Assessment of Neuropsychological Status (RBANS) Total Score Index explained by independent variables for valid RBANS $(n=60)$.

\begin{tabular}{|c|c|c|c|c|}
\hline \multirow[b]{2}{*}{ Variable (\%) } & \multicolumn{2}{|c|}{ RBANS Total Score } & \multicolumn{2}{|c|}{ RBANS Factor Score } \\
\hline & $\begin{array}{c}\text { Block Unique } \\
\text { Variance }\end{array}$ & $\begin{array}{c}\text { Variable Unique } \\
\text { Variance }\end{array}$ & $\begin{array}{l}\text { Block Unique } \\
\text { Variance }\end{array}$ & $\begin{array}{c}\text { Variable Unique } \\
\text { Variance }\end{array}$ \\
\hline Demographic & 1.5 & - & 3.7 & - \\
\hline Symptom Measures & 11.3 & - & 8.1 & - \\
\hline HIT-6 & - & 2.3 & - & 2.2 \\
\hline Total Variance & 16.7 & - & 16.2 & - \\
\hline Shared Variance & 0.7 & - & 2.8 & - \\
\hline
\end{tabular}

education. A re-evaluation of the data in the ArmisteadJehle and Hansen study showed that of those in their sample not enrolled in Command and General Staff College, 21.3 percent failed the RBANS EI. This percentage then appears commensurate in a military sample thought to be similar to that of the current study.

The finding that test taker effort is an important factor in neurocognitive test performance is certainly well founded in the current TBI literature. In fact, in a mixed clinical and forensic sample of mTBI subjects, Meyers et al. found that between 35 and 50 percent of the variance in neuropsychological testing could be accounted for by performance on various effort measures [35], which far trumped variance accounted for by psychiatric comorbidities or injury severity. Such a finding has been replicated numerous times in the TBI literature [32-34]. The current study then serves to extend these findings to a military sample. Relative to previous studies, the current data found that a lower amount of unique variance was accounted for by performance validity measures, but when shared variance is added to unique variance, current findings are generally comparable ( $16.3 \%$ unique plus $30.9 \%$ shared $=47.2 \%$ ) .

The current findings also highlight the notably suppressed scores across all RBANS scales of individuals who failed the RBANS EI relative to those who passed the measure. As demonstrated in Table 2, domain score differences reflect effect sizes $(d)$ of 0.89 to 1.56 between subjects who passed and failed the RBANS EI across all index scores. These data would then suggest that if providers do not consider test taker effort when interpreting scores in individuals with mTBI, resulting clinical decisions about diagnosis and treatment are likely to be inaccurate and stand a reasonable chance of misallocating clinical and administrative resources.

The current study contained a handful of limitations. First, the index of effort employed in this study likely lacks sensitivity and may have thus under-represented the actual variance accounted for by the effort of the patient. Future research could conduct a similar study with better validated performance validity tests, including the use of stand-alone performance validity or effort measures to replicate these findings. Second, the measure of neurocognitive ability employed in the current study, the RBANS, was a screening battery and more robust findings could be demonstrated with a more thorough neuropsychological battery. Efforts to these ends have been initiated by Armistead-Jehle and Buican [36], but replication appears indicated. Third, as shown in Table 3, a portion of the variance in the neurocognitive measure employed was left unexplained by the variables examined in the current study. Future research may look to include additional constructs to increase understanding of the associated factors contributing to neuropsychological test performances in this population, including the possible contribution of secondary gain.

To address our secondary aims, we repeated our logistic regression, selecting only those who passed the RBANS EI. In this subsample, a relatively small and nonsignificant portion of the variance in neurocognitive functioning was explained by demographic, injury, and symptom complaint variables included in this study 
(Table 4). The relative homogeneity of the sample (i.e., chronic mTBI with higher combat stress symptoms) and the somewhat narrow scope of psychological and somatic assessments may have contributed to this finding. Future research could expand the range of explanatory variables, including more thorough measures of psychological and somatic symptoms and general distress.

\section{CONCLUSIONS}

The current study replicated previous findings demonstrating that the influence of effort on neurocognitive testing exceeded other hypothesized factors, including psychiatric comorbidity and pain. Study results also demonstrate that despite the use of an effort measure with limited sensitivity, the base rate of PVT failure in a military sample was still notable. Taken together, these results support previous findings [37-38,54] highlighting the importance of PVTs in an Active Duty military population referred for mTBI evaluation.

\section{ACKNOWLEDGMENTS}

\section{Author Contributions:}

Study concept and design: D. B. Cooper, R. D. Vanderploeg,

A. O. Bowles.

Acquisition of data: D. B. Cooper, A. O. Bowles.

Analysis and interpretation of data: D. B. Cooper, R. D. Vanderploeg,

P. Armistead-Jehle, J. D. Lewis.

Drafting of manuscript: D. B. Cooper, P. Armistead-Jehle,

J. D. Lewis, R. D. Vanderploeg.

Critical revision of manuscript for important intellectual content:

D. B. Cooper, A. O. Bowles, R. D. Vanderploeg, J. D. Lewis,

P. Armistead-Jehle.

Statistical analysis: R. D. Vanderploeg.

Financial Disclosures: The authors have declared that no competing interests exist.

Funding/Support: This material was based on work supported in part by the DVBIC through contract support provided by the Henry M. Jackson Foundation for the Advancement of Military Medicine, Inc. Additional Contributions: The authors would like to acknowledge Hannah Castellaw, senior programmer/analyst, for her expertise in developing the TBI clinical database. Additionally, we would like to thank the following individuals for assistance with data collection and exemplary patient care: Kevin Manning, PhD; Melissa Kolodziej, MS; and Christine Fox, MS. A portion of this work was presented at the 2011 International Neuropsychological Society Annual Meeting in Boston, Massachusetts.

Institutional Review: This archival study was approved by the institutional review board at BAMC (BAMC IRB\#C.2009.117d.). This research has been conducted in compliance with all applicable Federal regulations governing the protection of human subjects.

Participant Follow Up: Because this is an archival study, the authors do not have the ability to notify subjects about the publication of this work.

Disclaimer: The opinions and assertions contained in this article are solely the authors' private ones and are not to be construed as official or reflecting the views of the DVBIC, U.S. Army, U.S. Air Force, Veterans Health Administration, or DOD. This manuscript was prepared by U.S. Government employees. It cannot be copyrighted and may be copied without restriction.

\section{REFERENCES}

1. Defense and Veterans Brain Injury Center. Department of Defense numbers for traumatic brain injury [Internet]. Silver Spring (MD): Defense and Veterans Brain Injury Center; [updated 2014 Sep 19; cited 2013 Apr 19]. Avaliable from: http://www.dvbic.org/TBI-Numbers.aspx

2. Brenner LA, Ivins BJ, Schwab K, Warden D, Nelson LA, Jaffee M, Terrio H. Traumatic brain injury, posttraumatic stress disorder, and postconcussive symptom reporting among troops returning from iraq. J Head Trauma Rehabil. 2010;25(5):307-12. [PMID:20042982] http://dx.doi.org/10.1097/HTR.0b013e3181cada03

3. Hoge CW, McGurk D, Thomas JL, Cox AL, Engel CC, Castro CA. Mild traumatic brain injury in U.S. Soldiers returning from Iraq. N Engl J Med. 2008;358(5):453-63. [PMID:18234750] http://dx.doi.org/10.1056/NEJMoa072972

4. Spencer RJ, Drag LL, Walker SJ, Bieliauskas LA. Selfreported cognitive symptoms following mild traumatic brain injury are poorly associated with neuropsychological performance in OIF/OEF veterans. J Rehabil Res Dev. 2010;47(6):521-30. [PMID:20848365] http://dx.doi.org/10.1682/JRRD.2009.11.0181

5. Drag LL, Spencer RJ, Walker SJ, Pangilinan PH, Bieliauskas LA. The contributions of self-reported injury characteristics and psychiatric symptoms to cognitive functioning in OEF/OIF veterans with mild traumatic brain injury. J Int Neuropsych Soc. 2012;18(3):576-84.

6. McCracken LM, Iverson GL. Predicting complaints of impaired cognitive functioning in patients with chronic pain. J Pain Symptom Manage. 2001;21(5):392-96.

[PMID:11369160] http://dx.doi.org/10.1016/S0885-3924(01)00267-6

7. Muñoz M, Esteve R. Reports of memory functioning by patients with chronic pain. Clin J Pain. 2005;21(4):287-91. [PMID:15951644] http://dx.doi.org/10.1097/01.ajp.0000173993.53733.2e

8. Hart RP, Wade JB, Martelli MF. Cognitive impairment in patients with chronic pain: The significance of stress. Curr 
Pain Headache Rep. 2003;7(2):116-26. [PMID:12628053] http://dx.doi.org/10.1007/s11916-003-0021-5

9. Moriarty O, McGuire BE, Finn DP. The effect of pain on cognitive function: A review of clinical and preclinical research. Prog Neurobiol. 2011;93(3):385-404.

[PMID:21216272]

http://dx.doi.org/10.1016/j.pneurobio.2011.01.002

10. Orff HJ, Drummond SP, Nowakowski S, Perils ML. Discrepancy between subjective symptomatology and objective neuropsychological performance in insomnia. Sleep. 2007;30(9):1205-11. [PMID:17910392]

11. Bonnet MH. Recovery of performance during sleep following sleep deprivation in older normal and insomniac adult males. Percept Mot Skills. 1985;60(1):323-34. [PMID:3982941] http://dx.doi.org/10.2466/pms.1985.60.1.323

12. Edinger JD, Glenn DM, Bastian LA, Marsh GR, Dailey D, Hope TV, Young M, Shaw E, Meeks G. Daytime testing after laboratory or home-based polysomnography: Comparisons of middle-aged insomnia sufferers and normal sleepers. J Sleep Res. 2003;12(1):43-52. [PMID:12603786] http://dx.doi.org/10.1046/j.1365-2869.2003.00335.x

13. Vignola A, Lamoureux C, Bastien CH, Morin CM. Effects of chronic insomnia and use of benzodiazepines on daytime performance in older adults. J Gerontol B Psychol Sci Soc Sci. 2000;55(1):P54-62. [PMID:10728124] http://dx.doi.org/10.1093/geronb/55.1.P54

14. Hoge CW, Auchterlonie JL, Milliken CS. Mental health problems, use of mental health services, and attrition from military service after returning from deployment to Iraq or Afghanistan. JAMA. 2006;295(9):1023-32. [PMID:16507803] http://dx.doi.org/10.1001/jama.295.9.1023

15. Lapierre CB, Schwegler AF, Labauve BJ. Posttraumatic stress and depression symptoms in soldiers returning from combat operations in Iraq and Afghanistan. J Trauma Stress. 2007;20(6):933-43. [PMID:18157882] http://dx.doi.org/10.1002/jts.20278

16. Vasterling JJ, Brailey K. Neuropsychological findings in adults with PTSD. In: Vasterling JJ, Brewin CR, editors. Neuropsychology of PTSD: Biological, cognitive, and clinical perspectives. New York (NY): Guilford Press; 2002. p. 178-207.

17. Kalska H, Punamäki RL, Mäkinen-Pelli T, Saarinen M. Memory and metamemory functioning among depressed patients. Appl Neuropsychol. 1999;6(2):96-107. [PMID:10379415] http://dx.doi.org/10.1207/s15324826an0602 5

18. King DA, Caine ED. Cognitive impairment and major depression: Beyond the pseudodementia syndrome. In: Grant I, Adams K, editors. Neuropsychological assessment and neuropsychiatric disorders. 2nd ed. New York (NY): Oxford University Press; 1996. p. 200-217.
19. Miller LS, Faustman WO, Moses JA Jr, Csernansky JG. Evaluating cognitive impairment in depression with the Luria-Nebraska Neuropsychological Battery: Severity correlates and comparisons with nonpsychiatric controls. Psychiatry Res. 1991;37(3):219-27. [PMID:1891505] http://dx.doi.org/10.1016/0165-1781(91)90058-W

20. Kanagaratnam P, Asbjørnsen AE. Executive deficits in chronic PTSD related to political violence. J Anxiety Disord. 2007;21(4):510-25. [PMID:16938424]

http://dx.doi.org/10.1016/j.janxdis.2006.06.008

21. Beckham JC, Crawford AL, Feldman ME. Trail making test performance in Vietnam combat veterans with and without posttraumatic stress disorder. J Trauma Stress. 1998;11(4):811-19. [PMID:9870231] http://dx.doi.org/10.1023/A:1024409903617

22. Koso M, Hansen S. Executive function and memory in posttraumatic stress disorder: A study of Bosnian war veterans. Eur Psychiatry. 2006;21(3):167-73.

[PMID:16139487]

http://dx.doi.org/10.1016/j.eurpsy.2005.06.004

23. Vasterling JJ, Brailey K, Constans JI, Sutker PB. Attention and memory dysfunction in posttraumatic stress disorder. Neuropsychology. 1998;12(1):125-33. [PMID:9460740] http://dx.doi.org/10.1037/0894-4105.12.1.125

24. Vasterling JJ, Duke LM, Brailey K, Constans JI, Allain AN Jr, Sutker PB. Attention, learning, and memory performances and intellectual resources in Vietnam veterans: PTSD and no disorder comparisons. Neuropsychology. 2002;16(1):5-14. [PMID:11853357] http://dx.doi.org/10.1037/0894-4105.16.1.5

25. Gilbertson MW, Gurvits TV, Lasko NB, Orr SP, Pitman RK. Multivariate assessment of explicit memory function in combat veterans with posttraumatic stress disorder. J Trauma Stress. 2001;14(2):413-32. [PMID:11469166] http://dx.doi.org/10.1023/A:1011181305501

26. Horner MD, Hamner MB. Neurocognitive functioning in posttraumatic stress disorder. Neuropsychol Rev. 2002; 12(1):15-30. [PMID:12090717] http://dx.doi.org/10.1023/A:1015439106231

27. Dikmen SS, Corrigan JD, Levin HS, Machamer J, Stiers W, Weisskopf MG. Cognitive outcome following traumatic brain injury. J Head Trauma Rehabil. 2009;24(6):430-38. [PMID:19940676] http://dx.doi.org/10.1097/HTR.0b013e3181c133e9

28. Belanger HG, Vanderploeg RD. The neuropsychological impact of sports-related concussion: A meta-analysis. J Int Neuropsychol Soc. 2005;11(4):345-57. [PMID:16209414] http://dx.doi.org/10.1017/S1355617705050411

29. Schretlen DJ, Shapiro AM. A quantitative review of the effects of traumatic brain injury on cognitive functioning. Int Rev Psychiatry. 2003;15(4):341-49. [PMID:15276955] http://dx.doi.org/10.1080/09540260310001606728 
30. Rohling ML, Binder LM, Demakis GJ, Larrabee GJ, Ploetz DM, Langhinrichsen-Rohling J. A meta-analysis of neuropsychological outcome after mild traumatic brain injury: Re-analyses and reconsiderations of Binder et al. (1997), Frencham et al. (2005), and Pertab et al. (2009). Clin Neuropsychol. 2011;25(4):608-23. [PMID:21512956] http://dx.doi.org/10.1080/13854046.2011.565076

31. McCrea M. Mild traumatic brain injury and postconcussion syndrome: The new evidence base for diagnosis and treatment. New York (NY): Oxford University Press; 2008.

32. Green P, Rohling ML, Lees-Haley PR, Allen LM 3rd. Effort has a greater effect on test scores than severe brain injury in compensation claimants. Brain Inj. 2001;15(12): 1045-60. [PMID:11712951] http://dx.doi.org/10.1080/02699050110088254

33. Moss A, Jones C, Fokias D, Quinn D. The mediating effects of effort upon the relationship between head injury severity and cognitive functioning. Brain Inj. 2003;17(5): 377-87. [PMID:12745710] http://dx.doi.org/10.1080/0269905031000070125

34. West LK, Curtis KL, Greve KW, Bianchini KJ. Memory in traumatic brain injury: The effects of injury severity and effort on the Wechsler Memory Scale-III. J Neuropsychol. 2011;5(Pt 1):114-25. [PMID:21366889] http://dx.doi.org/10.1348/174866410X521434

35. Meyers JE, Volbrecht M, Axelrod BN, Reinsch-Boothby L. Embedded symptom validity tests and overall neuropsychological test performance. Arch Clin Neuropsychol. 2011; 26(1):8-15. [PMID:21242283] http://dx.doi.org/10.1093/arclin/acq083

36. Armistead-Jehle P, Buican B. Evaluation context and symptom validity test performances in a U.S. military sample. Arch Clin Neuropsychol. 2012;27(8):828-39. [PMID:23047953] http://dx.doi.org/10.1093/arclin/acs086

37. Armistead-Jehle P, Hansen CL. Comparison of the Repeatable Battery for the Assessment of Neuropsychological Status Effort Index and stand-alone symptom validity tests in a military sample. Arch Clin Neuropsychol. 2011; 26(7):592-601. [PMID:21672936] http://dx.doi.org/10.1093/arclin/acr049

38. Armistead-Jehle P. Symptom validity test performance in U.S. veterans referred for evaluation of mild TBI. Appl Neuropsychol. 2010;17(1):52-59. [PMID:20146122] http://dx.doi.org/10.1080/09084280903526182

39. Nelson NW, Hoelzle JB, McGuire KA, Ferrier-Auerbach AG, Charlesworth MJ, Sponheim SR. Evaluation context impacts neuropsychological performance of OEF/OIF veterans with reported combat-related concussion. Arch Clin Neuropsychol. 2010;25(8):713-23. [PMID:20923860] http://dx.doi.org/10.1093/arclin/acq075
40. Larson EB, Kondiles BR, Starr CR, Zollman FS. Postconcussive complaints, cognition, symptom attribution and effort among veterans. J Int Neuropsychol Soc. 2013;19(1): 88-95. [PMID:23146625] http://dx.doi.org/10.1017/S1355617712000999

41. Cooper DB, Mercado-Couch JM, Critchfield E, Kennedy J, Vanderploeg RD, DeVillibis C, Gaylord KM. Factors influencing cognitive functioning following mild traumatic brain injury in OIF/OEF burn patients. NeuroRehabilitation. 2010;26(3):233-38. [PMID:20448313]

42. Randolph C, Tierney MC, Mohr E, Chase TN. The Repeatable Battery for the Assessment of Neuropsychological Status (RBANS): Preliminary clinical validity. J Clin Exp Neuropsychol. 1998;20(3):310-19. [PMID:9845158] http://dx.doi.org/10.1076/jcen.20.3.310.823

43. Casscells S. W. Health Affairs Memorandum: Consolidation of traumatic brain injury initiatives in the Department of Defense. Washington (DC): Department of Defense; 2007.

44. Randolph C. Repeatable Battery for the Assessment of Neuropsychological Status: Manual. San Antonio (TX): Psychological Corporation; 1998.

45. McKay C, Wertheimer JC, Fichtenberg NL, Casey JE. The Repeatable Battery for the Assessment of Neuropsychological Status (RBANS): Clinical utility in a traumatic brain injury sample. Clin Neuropsychol. 2008;22(2):228-41.

[PMID:17853143]

http://dx.doi.org/10.1080/13854040701260370

46. Silverberg ND, Wertheimer JC, Fichtenberg NL. An effort index for the Repeatable Battery for the Assessment Of Neuropsychological Status (RBANS). Clin Neuropsychol. 2007;21(5):841-54. [PMID:17676548] http://dx.doi.org/10.1080/13854040600850958

47. Blanchard EB, Jones-Alexander J, Buckley TC, Forneris CA. Psychometric properties of the PTSD Checklist (PCL). Behav Res Ther. 1996;34(8):669-73. [PMID:8870294] http://dx.doi.org/10.1016/0005-7967(96)00033-2

48. Keen SM, Kutter CJ, Niles BL, Krinsley KE. Psychometric properties of PTSD Checklist in sample of male veterans. J Rehabil Res Dev. 2008;45(3):465-74. [PMID:18629754] http://dx.doi.org/10.1682/JRRD.2007.09.0138

49. Cicerone K, Kalmar K. Persistent postconcussion syndrome: The structure of subjective complaints after mild traumatic brain injury. J Head Trauma Rehabil. 1995;10(3):1-17. http://dx.doi.org/10.1097/00001199-199510030-00002

50. Benge JF, Pastorek NJ, Thornton GM. Postconcussive symptoms in OEF-OIF veterans: Factor structure and impact of posttraumatic stress. Rehabil Psychol. 2009; 54(3):270-78. [PMID:19702425] http://dx.doi.org/10.1037/a0016736

51. Caplan LJ, Ivins B, Poole JH. The structure of postconcussive symptoms in 3 U.S. military samples. J Head Trauma 
Rehabil. 2010;25(6):447-58.

http://dx.doi.org/10.1097/HTR.0b013e3181d5bdbd

52. Ware JE Jr, Kosinski M, Bayliss MS, Bjorner JB. Measuring the impact of migraine and severe headache: Selecting a single, global item from the Headache Impact Test (HIT) item pool. Neurol. 2000;54(Suppl 3):A336.

53. Wilk JE, Thomas JL, McGurk DM, Riviere LA, Castro CA, Hoge CW. Mild traumatic brain injury (concussion) during combat: Lack of association of blast mechanism with persistent postconcussive symptoms. J Head Trauma Rehabil. 2010;25(1):9-14. [PMID:20051900] http://dx.doi.org/10.1097/HTR.0b013e3181bd090f

54. Lange RT, Pancholi S, Bhagwat A, Anderson-Barnes V, French LM. Influence of poor effort on neuropsychological test performance in U.S. military personnel following mild traumatic brain injury. J Clin Exp Neuropsychol. 2012; 34(5):453-66. [PMID:22273465]

http://dx.doi.org/10.1080/13803395.2011.648175
Submitted for publication May 3, 2013. Accepted in revised form March 26, 2014.

This article and any supplementary material should be cited as follows:

Cooper DB, Vanderploeg RD, Armistead-Jehle P, Lewis JD, Bowles AO. Factors associated with neurocognitive performance in OIF/OEF servicemembers with postconcussive complaints in postdeployment clinical settings. J Rehabil Res Dev. 2014;51(7):1023-34.

http://dx.doi.org/10.1682/JRRD.2013.05.0104

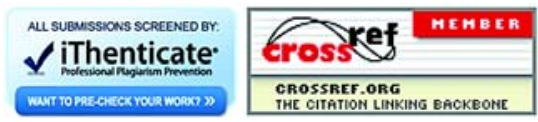


